\title{
Managing Emotional Requirements in a Context-Aware Mobile Application for Tourists
}

\author{
https://doi.org/10.3991/ijim.v12i2.7933 \\ Amir Dirin $(\bowtie)$ \\ Haaga-Helia University of Applied Sciences, Helsinki, Finland \\ amir.dirin@haaga-helia.fi \\ Teemu. H. Laine \\ Luleå University of Technology, Skellefteå, Sweden \\ Ari Alamäki \\ Haaga-Helia University of Applied Sciences, Helsinki, Finland
}

\begin{abstract}
The objective of this study was to unveil the importance of emotions and feelings in developing mobile-based tourism applications. We gathered and analyzed emotional requirements to develop a mobile context-aware application for tourists. Emotional requirements are non-functional requirements affecting users' emotional experiences around using applications, which are important for sustainable application usage. Many tourism applications exist, but were designed without considering emotional requirements or related UX factors and emotions. We developed a proof-of-concept prototype servicebased context-aware tourism application (SCATA), and users participated in the design and evaluation processes. Emotional requirements are key to sustainable usage, especially regarding security. This paper details the application design and evaluation processes, emotional requirements analysis in each design phase, and the emotional effects of content accessibility in the application's offline mode in unknown environments. The results show that trust, security, adjustability, and reliability are important factors to users, especially in unknown environments.
\end{abstract}

Keywords - context-aware mobile application, tourism application, usercentered design, emotions, emotional engagement

\section{Introduction}

Tourism and information technology (IT) are two entities with significant financial potential worldwide. Separately and together, they are changing the way societies operate [1]. The evolution of IT has brought consumer electronics from large objects to small, smart gadgets. Tourism is a major source of employment, revenue, international awareness, and opportunity for many regions of the world [2]. Despite contemporary technological advancements, there are still many obstacles that impact the 
design of robust tourism applications, such as offline access to resources and contextaware data access via mobile phones.

Smartphone penetration and smartphone usage among tourists are increasing rapidly [3], which has the potential to impact economic development [4]. According to the United Nations World Tourism Organization (UNWTO) [5], international tourist arrivals grew by $4.4 \%$ to almost 1.2 billion in 2015 . Tourists are often unable to access desktop computers while traveling in unfamiliar environments. Thus, mobile services can provide them with access to relevant digital services and guidance. Despite the existence of diverse smartphone platforms in the market, they all share common characteristics. Mobile technologies create a unique digital ecosystem for tourism through the convergence of media, telecoms, and IT industries [6].

Benckendorff et al. [7] classify major functions of mobile devices in tourism as follows. Informing is mainly used for destination guides, timetables, and currency conversion. Contextualizing is for interactive, real-time location awareness including live travel information, weather, real-time luggage and public transport tracking, flight status, and safety. Personalizing applies to recommender systems, trip planning/scheduling, and loyalty offers. Socializing includes mobile telephony with overthe-top content, mobile social media, and messaging; managing data occurs through data mining including, for example, visitor behavior, travel flows and patterns, and push notifications. Translating information includes, for example, real-time translations of brochures, signs, and speech. Purchasing travel products occurs through suppliers, travel intermediaries, and transactional mobile apps; gamifying applies to experiences, for example, of a rewards-based platform and review-based applications; augmenting the experience involves augmented reality travel guides; and reflecting on trips applies to social media platforms, geotagged photographs, and video.

However, mobile devices are not solely for tourism, as we have become increasingly dependent on smart gadgets. According to Andrews et al. [8], mobile device users reach for their devices 85 times per day and spend over 5 hours on mobile applications or on the Web each day, on average. According to a survey conducted by Ericsson [9] in 2015, there were 3.4 billion smartphone subscriptions, totaling 7.3 billion users, and the number of smartphone subscriptions is expected to double to 6.4 billion by 2021, with smartphone and tablet usage generating the fastest growth in terms of data traffic. Huff [10] states that the most significant difference between a computer and a mobile device is the user interface (UI), which evidently impacts the user experience. Despite their smaller screens, mobile devices provide several advantages compared to personal computers; for example, they offer more advanced participatory sensing and location-aware services, which are essential features for tourists. The tourism sector employs smartphones efficiently to assist tourists in managing their daily needs [11], familiarizing themselves with new cultures, and discovering new environments. However, designers of tourism mobile applications still lack a conceptual framework for effectively defining and managing users' emotional requirements. Tourism applications that fail to generate an emotional attachment for users will not be able to support sustainable usage.

Many attempts have been made to overcome the technological design and development challenges in designing tourism applications, as highlighted by Alamäki et al. 
[12], who demonstrate that tourism companies receive significant benefits from customizable mobile guide systems delivered as software-as-a-service (SaaS) solutions. Nevertheless, neither practitioners nor scholars have defined tourists' emotions and experiences.

This paper highlights the importance of non-functional, emotional requirements for designing and developing applications for tourists, which have an impact on the sustainability of a tourism application's usage. Accordingly, the paper identifies some of the most relevant emotional factors that have a direct impact on tourism application usage from the perspectives of potential users.

\section{Background of The Study}

\subsection{Mobile Services for Tourism}

Tourists are active users of mobile services and of digital marketing and ecommerce channels. Hence, the tourism business was at the forefront of developing ecommerce and Internet-based shopping solutions. TripAdvisor [13] survey shows that $42 \%$ of travelers used their mobile devices to book or plan a trip, and the most common uses of the tourism-based mobile application were researching restaurants (72\%), finding things to do (67\%), and reading reviews (64\%). Google's study [14] also points out the importance of mobile services and provides similar findings. For example, the results reveal that $78 \%$ of business travelers and $67 \%$ of leisure travelers use smartphones during a trip and that both groups focus this smartphone usage on gaining inspiration and researching. In addition, users often require navigation, guidance, points of interest, and route-specific information during their tourism activities. Tourists taking a vacation and walking in cities, or those who go hiking, biking, or kayaking, are frequently operating in unfamiliar environments, whether in urban areas or in the outdoors. Therefore, a typical aim of tourism-based mobile systems is to support most tourism activities [15] and [16]. In addition to supporting traditional activities associated with tourism, tourism companies could increase customer satisfaction by offering new types of digital guides and navigation aids as added-value services. Tourism companies today commonly offer their customers links to digital maps, such as Google Maps, or hard-copy maps containing a basic map highlighting points of interest and location information. In addition to basic tourism information, mobile services offer dynamic information to tourists, such as their position, service locations, distances between locations, and social and marketing information related to specific locations e.g., [17]. Existing tourism applications mainly provide information and support for city navigation services [18], where the use context of the mobile device does not significantly differ from typical mobile Internet usage, for example, when checking social media updates or answering phone calls while walking and traveling in city environments. Mobile applications also provide value for tourists engaging in outdoor tourism activities [19], and customized mobile guide services can be simultaneously delivered for use by several tourism companies [12]. 


\subsection{Emotional Requirements in Mobile Applications}

The characteristics of mobile services need to be considered while analyzing actual use and predicting future use, since physical, cognitive, emotional, security, and economic requirements vary between mobile service segments. They differ, for example, when using tourism applications as compared to mobile banking services. Dirin and Nieminen [20] categorize mobile application user experience into two eras. The first era (2000-2005) was characterized by technical facts [21], while the second era (2006-2010), which commenced after 2006, has gone beyond instrumental needs and requirements [22].

Hassenzahl and Tractinsky [22] categorize user experience of IT-related products into three main categories: (i) emotions, such as users' emotional expectations and needs; (ii) system design aspects, such as usability and the purpose and functionality of the system; and (iii) the context in which the product is in use, such as the social setting. Emotions play a crucial role in human-computer interaction and related technologies [23], [24] . Emotions are non-functional requirements, which Hassenzahl and Tractinsky [22] also refer to as "non-instrumental requirements." Furthermore, emotional experiences are feelings that inform people about the state of, and state changes in, their belief-desire system [25]. In other words, people have various beliefs and desires that they aim to fulfill (e.g., by engaging in tourism activities), and their emotional experiences or feelings indicate how those beliefs and desires have been met through the interaction with their surroundings. Kidwell et al. [26] show that emotions have a central role in marketing and sales actions. Therefore, tourism companies are developing mobile applications with the aim of increasing customer satisfaction and improving the marketing and sales success of their tourism services.

The findings of Kim et al. [27] and $\mathrm{Lu}$ et al. [28] indicate that although the user's perception of value is the most important determinant of the adaptation intention toward using mobile Internet services, enjoyment, which is an affective element, is also associated with the perceived value of mobile applications. Furthermore, Srite and Karahanna [29] show that high uncertainty avoidance as a cultural value is associated with social norms that drive the behavioral intention to use technological solutions. Thus, there are some cultural and social factors that emotionally influence the behavioral intention to use mobile applications. Alamäki and Dirin [30] state that the early involvement of key stakeholders in the design phase of mobile services ensures that end-users' emotional and cognitive needs will be more likely to be embedded in the final mobile service, which increases the potential behavioral intention to use the mobile service.

\subsection{Emotion Analysis}

The elicitation and measurement of emotions can be achieved by three approaches: subjective, behavioral, and physiological approaches [31]. We briefly describe these approaches in the following paragraphs.

Behavioral measurements cover versatile approaches that are used to measure user behavior. Two examples are the facial action coding system (FACS) [32], which 
measures facial poses (e.g., when we are happy we tend to smile), and the specific affect coding system (SPAFF) [33], which measures emotions during interactions, for example, between couples.

Physiological measurements allow for identifying how the body behaves when emotions change, for example, via the autonomic nervous system [34]. An example of a physiological measurement is detecting galvanic skin response via a sensor, which may be indicative of emotions such as happiness, surprise, disgust, anger, or fear [35].

Researchers often employ subjective measurements to measure subjective behavior using instruments such as questionnaires, rating scales, and experimental sampling. Scholars have also developed systematic subjective behavior measurement approaches, including the Positive and Negative Affect Schedule [36]. In such measures, users are asked how they currently feel (e.g., nervous, scared, inspired). Other methods, like the Stress Appraisal Measure [37], measure the user's stress level. Finally, with the help of experience sampling methods [38], it may be possible to capture people's emotions.

The term "emotional engagement," used in the present study, refers to the feelings that users construct through their emotions [39], and their cognitive development in terms of their values, trust, freedom, and ownership. Furthermore, the term "engagement" refers to the emotional bond that the user develops toward the application.

\section{$3 \quad$ Methodology and Evaluation Approaches}

This study comprises two distinct parts:

I. Concept development, in which we created a proof-of-concept service-based context-aware tourism application (SCATA) using the mLUX framework for mobile application development [13]. Short summaries of the applied methods and phases are presented in the following section.

II. Evaluation of the SCATA based on emotional engagement analysis (EEA) [40].

\subsection{Concept Development Methodology: The mLUX Framework}

To develop the context-aware tourism application concept, we applied the mLUX mobile application development framework [41]. The mLUX framework consists of three layers: the role-players, the processes, and the context of use. Figure 1 illustrates the iterative structure of mLUX, which consists of four phases: user study, data analysis, idea creation, and product concept. These iterative design processes facilitate data collection for both instrumental and non-instrumental user requirements. The instrumental requirements relate to users' expectations and needs that must be met for them to undertake essential tasks, and the non-instrumental requirements relate to users' emotional needs, such as their likes and dislikes regarding the application. To ease the design process when including both the instrumental and non-instrumental requirements, we utilized a scenario-based design.

In this framework, the stakeholders of the application are identified and studied during the user-study phase. Deploying various user-study methods allows for deter- 


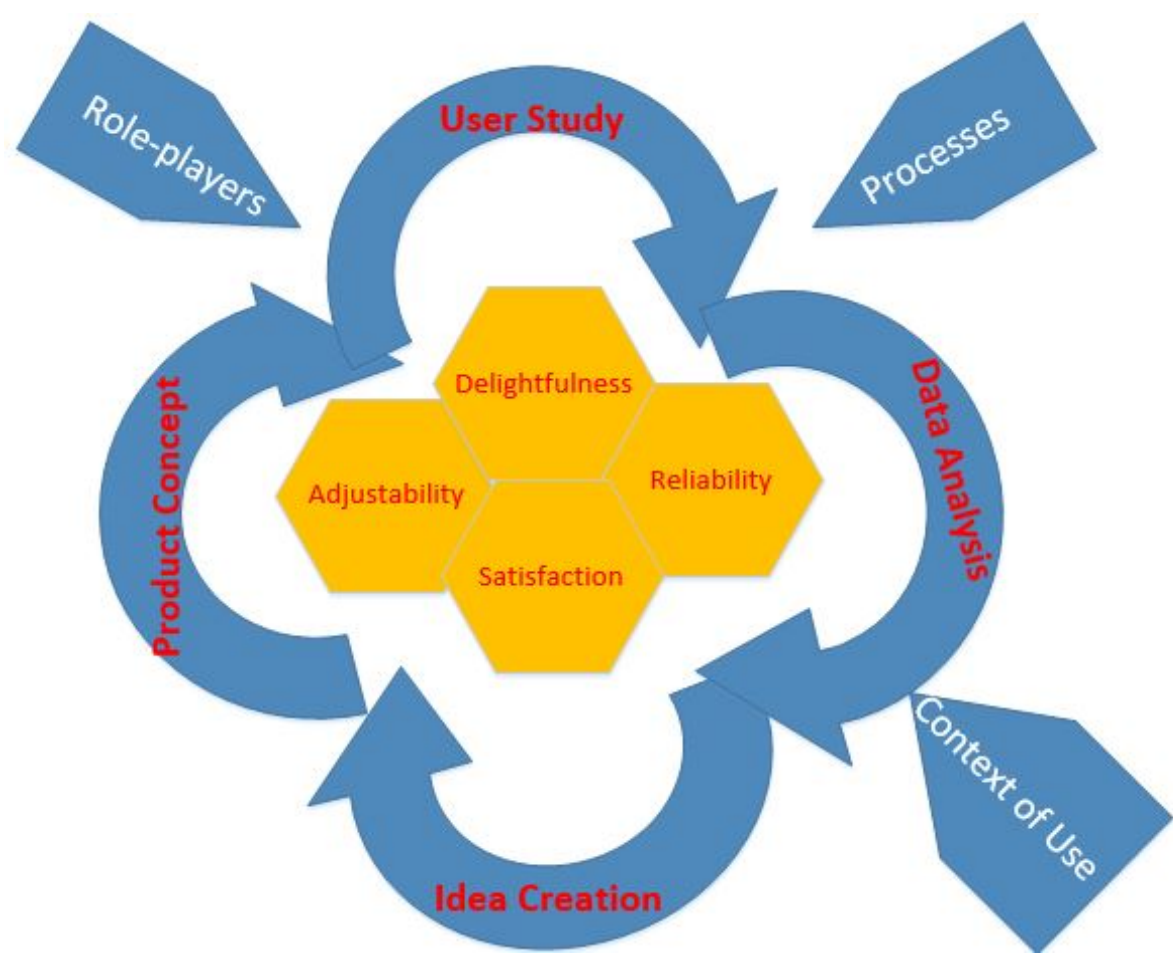

Fig. 1. The mLUX framework process

mining the users' real needs. The standard user-centered design (UCD) methodology [42] recommends assessing at least five target users [43]. The gathered userrequirement data are analyzed and classified in the data analysis phase using methods such as transcript coding, user task and environment analysis, and affinity diagrams. The user-study and data analysis phases help in identifying both functional and emotional requirements, such as users' expectations regarding the application, their motivations, emotional factors, and the application's context of use. Scenarios are then applied to develop a conceptual design for the application. A scenario consists of the identified requirements and users' expectations. The scenario is shared with target users to gain their early feedback on the concept behind the application. After scenario revisions are completed, a low/high fidelity prototype is developed and evaluated through a usability test with users. In the idea creation phase, subjective and behavioral measurements are taken regarding the application prototype.

The mLUX framework ensures that user experience factors, such as reliability, adjustability, delightfulness, and satisfaction, are considered in the target application. Reliability in mobile applications means supporting users in securely performing essential tasks. A trustworthy application ensures feelings of security in using the application and in interacting with the environment in question [44]. Adjustability in the context of mobile applications means that users are able to customize, personalize, and adjust the content and the application's UI according to their preferences. 
Hauksdóttir et al. [45] consider an application's adjustability to be measurable as early as in the requirements elicitation phase. Delightfulness in the context of mobile applications means that the application's functionalities and performance appeal to users. A delightful experience with an application means that the user is emotionally attached to the application. As Lucero et al. [46] suggest, a delightful UI provides a joyful experience. The delightful experience depends on the ease of comprehending the content and consistency in the application's behavior. Feeling delighted toward service delivery, as Kwong Ka Kei [47] states, can be expressed by a simple phrase, such as "Thank you." Satisfaction is an important user experience factor that significantly impacts the sustainable usage of mobile applications [48]. Accordingly, Kim and Ong's [49] findings reveal that in mobile applications, the content, usability, system assurance, service commitment, and membership in a community are considered high-level contributors to user satisfaction.

\subsection{Evaluation Methodology}

The application was assessed and evaluated with actual users in a controlled usability laboratory environment. Both the functionality of the application and its interactivity were evaluated. Such assessments help designers determine whether the application is usable and whether it satisfies the essential needs of its intended users. In addition to usability measurements, we deployed the emotional engagement analysis (EEA) method [40], which is based on subjective and behavioral measurements, and the four user experience factors described above. Together, these assessments indicate an application's usability, adaptivity, and how users will be emotionally attached to the application. The emphasis in this case study was on determining which emotional factors are essential for tourists and for tourism mobile applications.

\section{Concept Development}

The application concept was designed as a project assignment by a group of university students. The students applied the mLUX framework [41] during the project implementation process. A functional prototype of the application was developed as a student thesis project.

The application design was initiated by conducting user studies to elicit the needs and demands of potential users. Users were chosen from among tourists in Helsinki and exchange students at Haaga-Helia University of Applied Sciences. Semistructured interviews were carried out to obtain in-depth information about the users' requirements for the application. The interview sessions were recorded and transcribed for analysis. At the beginning of the interviews, the participants were briefed about the interview's goals and were asked to sign a consent form agreeing to the recording of the session and being contacted later, should further questions arise. The interview sessions lasted approximately 30 minutes.

Table 1 displays sample user profiles and their then-current use of mobile devices. Interviews were conducted with a total of $12(\mathrm{M}=2, \mathrm{~F}=10)$ users. The number of 
users exceeded the number of target users (5) recommended by the standard usercentered design methodology [42]. The age distribution varied from 21 years to 61 years (average: 36 ). Most of the users were tourists from other cities in Finland, and $90 \%$ had smartphones, while $83 \%$ considered themselves advanced users, well-versed in using communication applications such as Viber, WhatsApp, and Facebook. Conversely, novice users had minimal experience with smartphones and rarely downloaded applications or used a web browser.

We applied various data analysis methods on the data recorded from users. These methods helped us identify actions ande activities from the interview transcripts. The identified actions (e.g., performing a task) and activities (e.g., an action performed at a specific time) for each user were listed and categorized. Subsequently, we prepared a merged list of actions for all users. We applied affinity diagrams and brainstorming to compose a list of application requirements on the basis of commonly quoted actions. Table 2 shows samples of tasks that the users reported carrying out often with their mobile devices in different environments. The frequency indicates how often a task is carried out in a day.

Table 1. A sample of user profiles

\begin{tabular}{|c|c|l|l|}
\hline Age & $\mathbf{M} / \mathbf{F}$ & \multicolumn{1}{|c|}{ Smartphone user } & \multicolumn{1}{c|}{ Most used applications } \\
\hline 29 & F & Expert & Call and e-mail \\
\hline 58 & F & Novice & Call and SMS \\
\hline 61 & F & Expert & Facebook and e-mail \\
\hline$\ldots$ & $\ldots$ & $\ldots$ & $\ldots$ \\
\hline
\end{tabular}

Table 2. Samples of tasks, their frequencies, and environments

\begin{tabular}{|l|c|l|}
\hline \multicolumn{1}{|c|}{ Task } & Freq. & \multicolumn{1}{c|}{ Environment } \\
\hline Game & 9 & home/spare time during travel \\
\hline Calendar & 8 & home/outdoor \\
\hline Bank & 8 & home/outdoor \\
\hline$\ldots$ & $\ldots$ & $\ldots$ \\
\hline
\end{tabular}

We applied a scenario-based design [50] to represent the findings of the data analysis as a context-aware tourism application concept. This is an appropriate design approach for this context because it allows for presenting user behavior and interaction with the potential application as a short story. Thus, we created a scenario with embedded user personas to help represent characteristics of the target application users. The scenario was shared with users for assessment, thus allowing them to provide input on the concept design. An excerpt of the scenario is as follows:

John is an independent traveler just about travel to a foreign country. He starts off from Helsinki-Vantaa Airport and double-checks his flight's boarding time and gate information from his mobile application. With a single click, the app helps him navigate through the airport to the right gate. The app also gives him a reminder of the customs procedures of the destination country. 
The scenario was shared with five test users, three of whom had been previously interviewed and two of whom were new users. The scenario review sessions with users helped the designers understand the users' attitudes and opinions about the application concept. After the application concept was revised according to the users' feedback, a paper-based prototype was designed and evaluated with the scenario review test users. The paper prototype helped the designers test the initial user interface and its interactivity with test users. Finally, a functional application prototype was designed and developed on the basis of revisions to the paper prototype.

Figure 2 presents sample screenshots of the functional prototype of the SCATA. These screenshots represent the home screen of the SCATA when a tourist arrives at the airport/city in a foreign country. The user has a set of basic services at hand, such as the time, weather, a currency converter, local emergency phone numbers, departure and landing schedules, and the ability to search for places to visit.
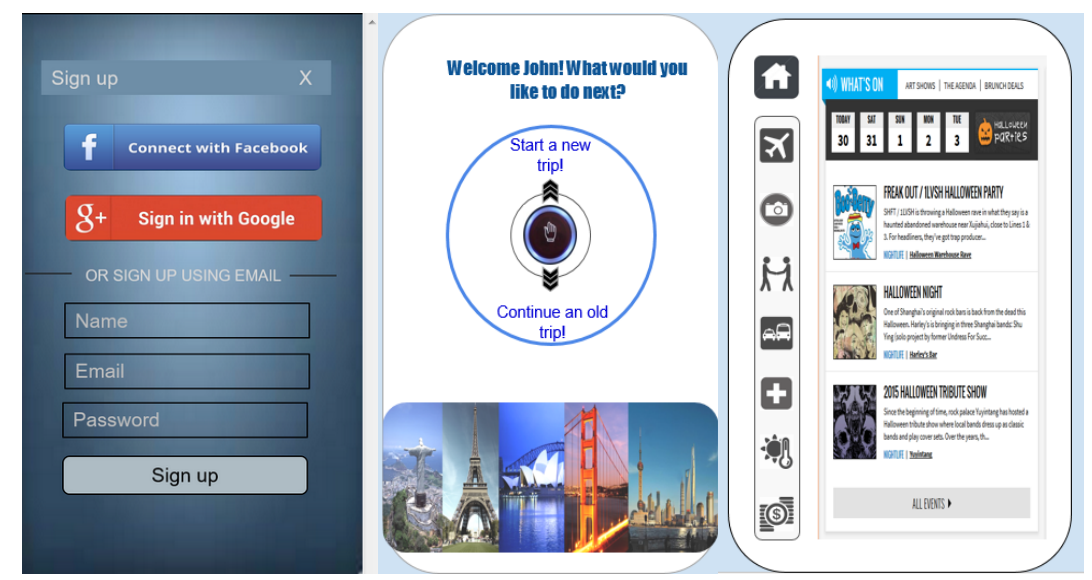

Fig. 2. Screenshots of the SCATA prototype

In this prototype, we only implemented a scenario in which the tourist reaches Dubai airport and connects to a free Wi-Fi network, after which the application adapts its behavior according to the tourist's profile and location. In the next steps of the scenario, the tourist arrives at the Dubai Mall, which prompts the application to display the homepage of the Dubai Mall. The tourist can easily find the hottest deals, specific products, or shops of interest, and will be given navigational information to find them. Additionally, the tourist can choose to see navigational instructions to the nearest exit or bus stop.

The SCATA prototype was implemented by applying technologies such as Java, SQL, and Python, and using the model-view-controller architectural pattern. The application content was provided as a collection of web services to SCATA users depending on the user's context, and the recommended services were personalized by a machine learning algorithm (Naïve Bayes classifier). The SCATA services were designed for using open data and freely available application programming interfaces (APIs), such as weather services and currency exchange rate API. 


\section{$5 \quad$ Usability Assessment and Emotional Engagement Analysis}

\subsection{SCATA Usability Assessment}

The application usability evaluation was carried out at a usability lab at HaagaHelia University of Applied Sciences. We applied elements from Nielsen's heuristic evaluation guidelines [51] to test the application's functionalities and interactivities while observing the users from an observation room. The test users, who were mainly tourists and exchange students in Helsinki, were given predefined tasks to carry out during the test. All test activities were recorded after the test users signed their written consent forms. Examples of test tasks are as follows: Find the nearest hospital, Find a list of museums, Contact a local administrator, Find a list of restaurants, and Find a list of events.

In the usability assessment, we mainly measured how the users performed the task, what kinds of problems they were facing, and how they overcame the confusion that they might have encountered with the application. We also studied how the users behaved in dysfunctional application situations (behavior analysis). After each test session, we conducted a post-interview to learn more about the users' attitudes and experiences with the application (subjective analysis).

The test users were satisfied with the application's performance and functionalities. They found the application easy to use and its UI design "calm and nice." However, they complained about the small font size and reported confusion arising in relation to some parts of the application, such as locating a restaurant. The only inconsistency in the application design was that most of the time, the users had to click to perform an action, yet for one action, which utilized open data, they had to swipe the screen instead of clicking. The users provided many recommendations for improvements, such as adding search functionality, terminology corrections, being able to change their profile settings, consistency when performing actions, and the ability to save plans for their trips. We updated the prototype in accordance with the usability assessment results.

\subsection{Emotional Engagement Analysis of the SCATA}

In the following, we present the results of the EEA, which are based on subjective and behavioral measurements of the SCATA prototype.

Subjective Analysis. Two important questions related to emotional factors were under investigation during the design and development processes:

1. How do travelers value the feelings of trust and reliability when they travel?

2. Do travelers feel secure when they have access to the application content at any time and in any place?

The subjective analysis in this study was based on user study research during the elicitation, scenario revision, and pre- and post-interview phases. Therefore, the analysis and findings are based on verbatim feedback from the users. Our analysis of the 
collected data revealed that tourists were often concerned about uncertainty regarding the target location, especially when they had not previously visited the location. Such feelings of uncertainty and stress not only emerge when tourists arrive at their destination but tend to arise well before their trip has even started. Moreover, tourists were concerned about issues such as getting to the airport, vaccination information, and visa status. Feelings of stress also emerge once tourists reach their destination, for example, when they try to get to their hotel, find the right transportation, and get connected to the Internet. Additionally, they expressed often being concerned about the safety of their destination. Therefore, always being connected to the Internet and getting the latest updates helps tourists overcome some of these major sources of stress.

The subjective analysis helped us learn about the users' emotional needs, such as trust, satisfaction, and application reliability during various stages of traveling. For example, during the user study phase, the users verbally emphasized their negative experiences with existing tourism applications because they were not usable in the offline mode. In the data analysis phase, we realized that both the trust and reliability aspects of the SCATA were main concerns for users in the offline mode when abroad. Table 3 summarizes the emotional requirements that resulted from the users' expectations (mental model) of the SCATA's performance and usage. These were acquired by applying subjective analysis to assess the users' emotional needs relating to the target application.

Table 3. Summary of the SCATA's emotional requirements

\begin{tabular}{|l|l|l|l|}
\hline $\begin{array}{l}\text { Emotional require- } \\
\text { ments (UX factors) }\end{array}$ & \multicolumn{1}{|c|}{ Description } & \multicolumn{1}{|c|}{ Key features } & $\begin{array}{l}\text { Architectural functionali- } \\
\text { ty }\end{array}$ \\
\hline $\begin{array}{l}\text { Reliability and trust- } \\
\text { fulness }\end{array}$ & $\begin{array}{l}\text { The user feels that the } \\
\text { application is trustful } \\
\text { (e.g., relevant and } \\
\text { accurate information is } \\
\text { accessible when need- } \\
\text { ed) }\end{array}$ & $\begin{array}{l}\text { Data accessibility in offline } \\
\text { mode; fulfills the user's } \\
\text { needs in various contexts }\end{array}$ & $\begin{array}{l}\text { Offline mode, local stor- } \\
\text { age, behavioral analysis }\end{array}$ \\
\hline Adjustability & $\begin{array}{l}\text { The application is } \\
\text { customizable accord- } \\
\text { ing to the user's pref- } \\
\text { erences }\end{array}$ & $\begin{array}{l}\text { The application is capable of } \\
\text { adjusting the content and the } \\
\text { UI according to the user's } \\
\text { context and requirements }\end{array}$ & $\begin{array}{l}\text { The user can customize the } \\
\text { UI, such as its look and } \\
\text { feel; machine learning } \\
\text { helps adjust the application } \\
\text { content on the basis of the } \\
\text { context of use }\end{array}$ \\
\hline Delightfulness & $\begin{array}{l}\text { The user has fun when } \\
\text { using the application }\end{array}$ & $\begin{array}{l}\text { The user is emotionally } \\
\text { attached to the application } \\
\text { owing to its provision of } \\
\text { adjustability, UI preferences, } \\
\text { and proper content based on } \\
\text { the user's context, and sup- } \\
\text { porting the user's needs }\end{array}$ & $\begin{array}{l}\text { The user has a positive } \\
\text { experience (e.g., content is } \\
\text { provided to the user ac- } \\
\text { cording to the context) }\end{array}$ \\
\hline Satisfaction & $\begin{array}{l}\text { The essential travel } \\
\text { needs are provided on } \\
\text { the basis of the user's } \\
\text { context }\end{array}$ & $\begin{array}{l}\text { It fulfills the user's individual } \\
\text { travel needs, such as essential } \\
\text { tourist information, social } \\
\text { information, and context } \\
\text { information }\end{array}$ & $\begin{array}{l}\text { Open data and existing } \\
\text { apalysis }\end{array}$ \\
\hline and user's behavioral \\
\hline
\end{tabular}


Behavioral Analysis. We conducted a behavioral analysis using videos and semistructured interviews, which we recorded during the usability evaluation sessions. For example, we studied how the users reacted in different test-case situations, especially during tasks relating to trust and reliability. Therefore, the data presented in this study in relation to the behavioral analysis were derived from an analysis carried out after the usability test had been conducted. The main difference between the in-session behavioral observation and post-session observation is that we did not have access to test users if we wanted further clarification regarding specific behaviors. The analyzed data are based on the test users' actions as well as on their behavioral and verbal communication during the test sessions. It is important to highlight that the test sessions took place in a controlled usability lab, and thus the findings are only valid in this context.

The analyses of videos and interviews indicated that test users were concerned about unknown environments. They divulged that often learn about new environments by using Google Maps. One user stated the following: "I use often Google maps to learn about the destination." Indeed, almost all interviewed users recommended that tourists have direct access to Google Maps. Google Maps was the main channel for building trust toward an unknown environment. Some test users mentioned that they print the maps of important places in advance. As one user stated, "I often print the maps in advance, but I can't print the whole city [map] in advance." However, this does not solve the problem if they want to explore new places at the destinations: "The problem is that I do not have access to a printer or Internet to explore new places at the destination." This was also observed in video clips of the usability sessions, when test users sought Google Maps to obtain information about a specific place.

Test users highlighted other user experience factors, such as adjustability, delightfulness, reliability, and satisfaction. Furthermore, they considered customizability to be a positive feature of the application. All users completed the tasks before the allotted time expired. They appeared to be having fun with the application. According to one user, "it was easy to use and fun to play with." The test users mentioned that they trusted the application, as it allowed them to retrieve whatever information they had saved and provided relevant information in their context: "At least in the lab environment, the application performs exactly how I expect it to perform."

\section{Discussion}

In this study, we aimed to demonstrate that without considering the emotional requirements of applications (e.g., tourism applications), users' essential needs would not be satisfied, thus leading the users to ignore the application when they need it the most. We discovered that feelings of insecurity emerge especially in unknown environments. This insecurity often results from unawareness of one's surroundings and of things that are going on in the new environment. This feeling develops especially in environments where tourists do not have any acquaintances, do not know the language, and yet where they spend most of their travel time, such as while sightseeing 
or visiting shopping centers and museums. This issue was also highlighted by users in the requirement elicitation phase of the application design though statements such as "I have downloaded many applications, but I cannot use them in a foreign country." Therefore, a tourism application that overcomes awareness issues by providing proper content based on the context will help tourists overcome this feeling of insecurity. This is an essential step toward devising a trustful application concept for tourists.

While traveling, mobile subscribers often use their mobile phone in the offline mode due thigh data roaming costs. Consequently, tourists are often disconnected and rely merely on device's GPS and in offline maps mode. Even though maps and GPS are frequently used by youths, who know that these features are free of charge, others are often skeptical and are, therefore, reluctant to use GPS and maps due to possible costs that may be incurred. If a user feels there is no value in using an application in the context in which they want to use, then they will be reluctant to use the application no matter how expensive it was to purchase. This indicates that the fulfillment of essential needs and the continued usage aspect are strongly interrelated. One might conclude that the reluctance to use existing tourist applications stems from their failure to fulfill the tourist's essential needs in the contexts where they need them the most. These issues were also highlighted during the user study phase that users suggested shortcomings, such as the cost of data roaming, the poor performance of the application, and the lack of benefits when using it abroad. Therefore, the proposed SCATA prototype was designed and developed to overcome the aforementioned constraints by making the application context-aware and able to function in the offline mode, thus enabling users to avoid extra charges. The information that the application provides is based on the user profile and behavioral analysis. Therefore, the content is customized to each user according to their preferences. An application that anticipates and eradicates feelings of uncertainty will help tourists feel secure, which will obviously have an impact on their overall satisfaction level 1

Table 4 presents a summary of a tourist's activities before, during, and after a trip. This information sheds light on the required actions, thereby allowing for recommending proper solutions.

Software development methodologies, such as UCD, focus on collecting users' essential needs and requirements to ease and promote the way of handling tasks. These methodologies have already proven to be efficient, resulting in products that satisfy the users' essential needs. However, these methodologies often fail to deal with nonfunctional needs and requirements, such as trust, security, or delight. These are emotional requirements that are often ignored or only raised during the final phase of product usability evaluations. This study addressed the importance of gathering emotional requirements for tourism-type applications. Applications that allow users to increase their awareness of their surroundings and the context in which they interact will help with application sustainability. Figure 3 presents the emotional requirements (i.e., trust, security, reliability, and adjustability) involved in tourism applications as identified in this study. These requirements were recognized in the context in which we conducted the study. In another context, we probably would have a different set of emotional requirements. 
Table 4. Framework for integrating emotional non-functional requirements into the design of a mobile tourism application

\begin{tabular}{|c|c|c|c|}
\hline User Journey & Before the trip & During the trip & After the trip \\
\hline $\begin{array}{l}\text { Activities when using } \\
\text { the tourism application }\end{array}$ & $\begin{array}{l}\text { - Plan trip } \\
\text { - Search information } \\
\text { - Select target locations } \\
\text { - Read reviews } \\
\text { - Compare alternatives } \\
\text { - Communicate }\end{array}$ & $\begin{array}{l}\text { - Select points of interest } \\
\text { - Navigate } \\
\text { - Read reviews } \\
\text { - Compare alternatives } \\
\text { - Need help } \\
\text { - Document and share } \\
\text { experiences } \\
\text { - Communicate }\end{array}$ & $\begin{array}{l}\text { - Give feedback } \\
\text { - Share experiences } \\
\text { - Recall emotional experi- } \\
\text { ences } \\
\text { - Dream of a new trip } \\
\text { - Begin to plan a new trip }\end{array}$ \\
\hline $\begin{array}{l}\text { Defining the context } \\
\text { and situational re- } \\
\text { quirements }\end{array}$ & $\begin{array}{l}\text { - Relax at home with Wi- } \\
\text { Fi access } \\
\text { - Excited but slightly } \\
\text { nervous at the airport } \\
\text { with } 3 \mathrm{G} \text { access }\end{array}$ & $\begin{array}{l}\text { - Relax at hotel with Wi- } \\
\text { Fi access } \\
\text { - Excited but somewhat } \\
\text { tired at airport with } 3 \mathrm{G} \\
\text { access } \\
\text { Excited but a little } \\
\text { worried at the tourism } \\
\text { location with an offline } \\
\text { model }\end{array}$ & $\begin{array}{l}\text { - Excited and relaxed at } \\
\text { the airport with } 3 \mathrm{G} \text { ac- } \\
\text { cess } \\
\text { - Relax at home with Wi- } \\
\text { Fi access }\end{array}$ \\
\hline $\begin{array}{l}\text { Emotional non- } \\
\text { functional require- } \\
\text { ments }\end{array}$ & \multicolumn{3}{|l|}{$\begin{array}{l}\text { - Reliability and trustfulness } \\
\text { - Adjustability } \\
\text { - Delightfulness } \\
\text { - Satisfaction }\end{array}$} \\
\hline Concept planning & \multicolumn{3}{|c|}{$\begin{array}{l}\text { The non-functional requirements operationalized and concretized in the concept } \\
\text { plan through, e.g., the use of case descriptions }\end{array}$} \\
\hline \begin{tabular}{|l|} 
Examples of architec- \\
tural and functional \\
requirements enabling \\
the desired primary \\
emotional experience
\end{tabular} & \multicolumn{3}{|c|}{$\begin{array}{l}\text { - Hybrid mobile architectural solution and proven development framework select- } \\
\text { ed according to the understanding of touchpoints (reliability and trustfulness, } \\
\text { adjustability, delightfulness, satisfaction) } \\
\text { - Interactive UI (satisfaction) } \\
\text { - Rich media and Web } 2.0 \text { content structure (delightfulness, satisfaction) } \\
\text { - Settings for hiding and showing content, data, UI elements, and functionalities } \\
\text { (adjustability, satisfaction) } \\
\text { - Sensor data from speed, distance, and others (delightfulness, satisfaction) } \\
\text { - Geo-location for navigation, interest points, and positioning (satisfaction) } \\
\text { - Context awareness and usage monitoring as machine learning (adjustability, } \\
\text { delightfulness, satisfaction) } \\
\text { - APIs and access to web map services and other open data (reliability and trust- } \\
\text { fulness, satisfaction) } \\
\text { - Local storage for saving maps and selected content for offline use (adjustable, } \\
\text { satisfaction) } \\
\text { - Notifications based on the context, such as checking in and local deals (delight- } \\
\text { fulness, satisfaction) } \\
\text { - Recommendation agent and social search enabling community building (delight- } \\
\text { fulness, satisfaction) }\end{array}$} \\
\hline
\end{tabular}

Trust is an essential and multidimensional factor that influences user and customer behavior, e.g., [52], [53]. We found that users are concerned when using a tourist application in an unfamiliar environment. In particular, they must be able to trust that their mobile application is providing accurate and relevant information and guidance. Feelings of trust and security are thus interrelated, and a trustworthy application seems to influence the feeling of being secure. The SCATA application is aimed at 


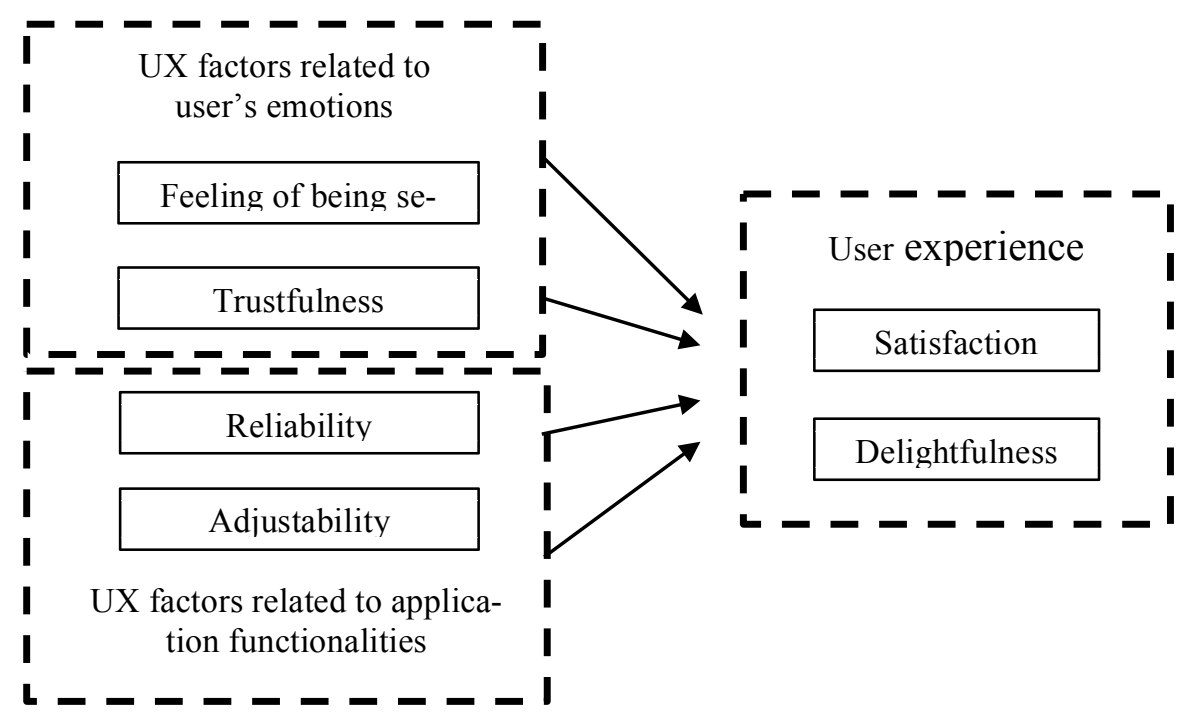

Fig. 3. Trust and feeling of being secure as extended user experience factors in mobile tourism applications

satisfying tourists' essential traveling needs, raising awareness (e.g., by providing relevant information on the context), and providing full control of the application so that it can operate in the offline mode, thus making users feel more secure.

The user experience factors associated with the application depend on the context of the use of the application. In the context of tourism, the results of this study demonstrate that the user expects to gain a feeling of security when using the application on their mobile device. Additionally, the perceived trustfulness of the application is an extended emotional requirement that users have. However, users expect to have an application on their mobile device that is reliable and customizable, based on their preferences. The user experience and emotional factors besides the other functionalities of the application make the user feel satisfied and delighted.

\section{Conclusions}

The results of this study reflect the importance of non-functional emotional requirements of tourism mobile applications. Meeting emotional requirements results in the user's emotional engagement with the application; hence, the user trusts the application and enjoys using it. Therefore, gathering emotional requirements plays an important role when designing and developing a sustainable mobile application. Thus, emotional requirements should not be reviewed only in terms of UI design but also as an approach for engaging users emotionally with the application. 
This paper identified and elaborated four major user experience factors that impact a tourism application's sustainable usage. These emotional factors were recognized on the basis of the context in which we conducted the study. In different situations and study environments, additional emotional factors may be identified.

The feeling of being secure impacts tourists in unfamiliar environments. This is aligned with Androulidakis and Kandus' [54] findings that users who trust their mobile applications tend to be less concerned with security issues. The feeling of trust is developed when the user feels that the application has value, efficiency, and effectiveness in various contexts.

This study contributes especially to the design of digital services and mobile applications where the understanding of users' emotional factors is becoming increasingly important due to their integral and more intelligent role in assisting human activities. Mobile applications as end terminals and their artificial intelligence-based back-end systems are playing a more important role in assisting, recommending, and supporting our daily activities. Thus, the rapidly growing role of artificial intelligence in digital services and mobile applications merits further examination especially from the viewpoint of emotional factors.

There are limitations in generalizing the findings of this study, as the number of interviewees and participants in the concept creation and application testing was quite small, as the qualitative concept creation approach was employed. Although users travel and operate internationally, the users in this study mainly represent the Nordic travelling and business culture, which may cause cultural limitations concerning trust and the feeling of being secure

This study should encourage researchers to quantitatively explore and generalize factors concerning emotional trust and the feeling of security in the context of mobile device use in unfamiliar situations and environments. More research would be appropriate to determine how different user interface designs influence users' emotional trust and feeling of being secure. Experimental studies, where researchers analyze users' behavioral intention to consume content displayed in an application or to purchase products or services in electronic marketplaces, would provide direct theoretical and practical knowledge concerning those emotional factors. This would make a unique contribution when designers create user interfaces and software functionalities for financial and commercial services, where the end users are dealing with credit cards, money transfers, and other purchasing-related activities.

In future research, we aim to develop and test the application in a real environment. Furthermore, as the results presented in this paper are based on the context where this study was conducted, we aim to expand the user study and data analysis in different contexts to validate the findings.

\section{References}

[1] D. Leung and R. Law, "Information technology, tourism," in Encyclopedia of Tourism, vol. 29, no. 3, 2015, pp. 885-886. https://doi.org/10.1007/978-3-319-01669-6 108-1

[2] P. Benchekdorff, D. Desenmaier, and P. Sheldon, Tourism Information Tecchnology. 2nd Edition. Malta: Gutenberg Press., 2014. 
[3] D. Wang, S. Park, and D. R. Fesenmaier, "The Role of Smartphones in Mediating the Touristic Experience,” J. Travel Res., vol. 51, no. 4, pp. 371-387, 2012. https://doi.org/10.1177/0047287511426341

[4] M. Hübler and R. Hartje, "Are smartphones smart for economic development?," Econ. Lett., vol. 141, pp. 130-133, 2016. https://doi.org/10.1016/j.econlet.2016.02.001

[5] World Tourism Organization (UNWTO), "UNWTO Tourism Highlights," 2016.

[6] K. Schwab, "The World Economic Forum," World Economic Forum, 2015. [Online]. Available: http://www3.weforum.org/docs/WEF_GlobalCompetitivenessReport_201415.pdf.

[7] P. J. Benckendorff, P. J. Sheldon, and D. R. Fesenmaier, Tourism information technology: Second edition. 2014. https://doi.org/10.1079/9781780641850.0000

[8] S. Andrews, D. A. Ellis, H. Shaw, and L. Piwek, "Beyond self-report: Tools to compare estimated and real-world smartphone use," PLoS One, vol. 10, no. 10, 2015. https://doi.org/10.1371/journal.pone.0139004

[9] Ericsson, "Ericsson mobility report: On the pulse of the networked society. Mobile World Congress Edition February 2016," 2016.

[10] K. C. Huff, "The comparison of mobile devices to computers for web-based assessments," Comput. Human Behav., vol. 49, pp. 208-212, 2015. https://doi.org/10.1016/j.chb.2015. 03.008

[11] E. Šimková and J. Holzner, "Motivation of Tourism Participants," Procedia - Soc. Behav. Sci., vol. 159, pp. 660-664, 2014. https://doi.org/10.1016/j.sbspro.2014.12.455

[12] A. Alamäki, A. Dirin, J. Huotari, and N. Korhonen, "Rapid Prototyping of A Mobile SAAS Application,” J. Mob. Multimed., vol. 12, no. 1, pp. 138-158, 2016.

[13] TripAdvisor, "TripBarometer Connected Traveler," 2015. [Online]. Available: http://ir.tripadvisor.com/releasedetail.cfm?ReleaseID=919990.

[14] C. Vandeviver, "Applying Google Maps and Google Street View in criminological research," Crime Sci., vol. 3, no. 13, pp. 1-16, 2014.

[15] D. Gavalas and M. . Kenteris, "web-based pervasive recommendation system for mobile tourist guides," Pers. Ubiquitous Comput., vol. 15, pp. 759-770, 2011. https://doi.org/10.1007/s00779-011-0389-x

[16] H. Kennedy-Eden and U. Gretzel, "A taxonomy of mobile applications in tourism," eReview Tour. Res., vol. 10, no. 2, pp. 47-50, 2012.

[17] C. Lamsfus, D. Wang, A. Alzua-Sorzabal, and Z. Xiang, "Going Mobile: Defining Context for On-the-Go Travelers,” J. Travel Res., vol. 54, no. 6, pp. 691-701, 2015. https://doi.org/10.1177/0047287514538839

[18] D. Gavalas, C. Konstantopoulos, K. Mastakas, and G. Pantziou, "Mobile recommender systems in tourism," Journal of Network and Computer Applications, vol. 39, no. 1. pp. 319-333, 2014. https://doi.org/10.1016/j.jnca.2013.04.006

[19] A. Alamäki and A. Dirin, "Designing Mobile Guide Service for Small Tourism Companies Using User Centered Design Principle," in Proceedings of the International Conference on Computer Science, Computer Engineering, and Social Media, Thessaloniki, Greece, 2014, 2014, pp. 47-58.

[20] A. Dirin and M. Nieminen, "User Experience Evolution of M-Learning Applications," in 9th internation conference on computer supported Education 21-23 April, 2017, p. 9.

[21] J. J. Garrett, “The Elements of User Experience," p. 2000, 2000.

[22] M. Hassenzahl and N. Tractinsky, "User experience - a research agenda," Behaviour \& Information Technology, vol. 25, no. 2. pp. 91-97, 2006. https://doi.org/10.1080/0144929 0500330331

[23] E. Hudlicka, "To feel or not to feel: The role of affect in human-computer interaction," Int. J. Hum. Comput. Stud., vol. 59.1, p. 32, 2003. https://doi.org/10.1016/S10715819(03)00047-8 
[24] R. a. Calvo, "Latent and Emergent Models in Affective Computing," Emot. Rev., vol. 2, no. 3, pp. 288-289, 2010. https://doi.org/10.1177/1754073910368735

[25] R. Reisenzein, "Emotional Experience in the Computational Belief-Desire Theory of Emotion,” Emot. Rev., vol. 1, no. 3, pp. 214-222, 2009. https://doi.org/10.1177/1754073 909103589

[26] B. Kidwell, D. M. Hardesty, B. R. Murtha, and S. Sheng, "Emotional Intelligence in Marketing Exchanges," J. Mark., vol. 75, no. 1, pp. 78-95, 2011. https://doi.org/10.1509/ jmkg.75.1.78

[27] H. W. Kim, H. C. Chan, and S. Gupta, "Value-based Adoption of Mobile Internet: An empirical investigation," Decis. Support Syst., vol. 43, no. 1, pp. 111-126, 2007. https://doi.org/10.1016/j.dss.2005.05.009

[28] J. Lu, C. Liu, and J. Wei, "How Important Are Enjoyment and Mobility for Mobile Applications?," J. Comput. Inf. Syst., vol. 57, no. 1, pp. 1-12, 2017. https://doi.org/10.1080/ 08874417.2016 .1181463

[29] M. Srite and E. Karahanna, "The Role of Espoused National Cultural Values in Technology Acceptance," MIS Q., vol. 30, no. September, pp. 679-704, 2006. https://doi.org/10.2307/25148745

[30] A. Alamäki and A. Dirin, "The stakeholders of a User-Centered Design Process in Mobile Service development,” Int. J. Digit. Inf. Wirel. Commun., vol. 5, no. 4, pp. 270-284, 2015.

[31] K. R. Scherer, "What are emotions? And how can they be measured?," Soc. Sci. Inf., vol. 44, no. 4, pp. 695-729, 2005. https://doi.org/10.1177/0539018405058216

[32] P. Ekman and W. V. Friesen, "The Facial Action Coding System.," Consulting, 1978.

[33] J. a Coan and J. M. Gottman, "The Specific Affect Coding System (SPAFF).," Handb. Emot. elicitation assessment., pp. 267-285, 2007.

[34] S. D. Kreibig, "Autonomic nervous system activity in emotion: A review," Biol. Psychol., vol. 84, no. 3, pp. 394-421, 2010. https://doi.org/10.1016/j.biopsycho.2010.03.010

[35] W. Guanghua, L. Guangyuan, and H. Min, "The analysis of emotion recognition from GSR based on PSO," 2010. [Online]. Available: http://ieeexplore.ieee.org/document/566325.

[36] D. Watson, L. a. Clark, and a. Tellegen, "Positive and negative affect schedule (PANAS)," J. Pers. Soc. Psychol., vol. 54, pp. 1063-1070, 1988. https://doi.org/10.1037/ 0022-3514.54.6.1063

[37] E. Peacock and P. Wong, "The stress appraisal measure (SAM): a multidimensional approach to cognitive appraisal," Stress Med., vol. 6, no. 3, pp. 227-236, 1990. https://doi.org/10.1002/smi.2460060308

[38] T. S. Conner, H. Tennen, W. Fleeson, and L. F. Barrett, "Experience Sampling Methods: A Modern Idiographic Approach to Personality Research.," Soc. Personal. Psychol. Compass, vol. 3, no. 3, pp. 292-313, 2009. https://doi.org/10.1111/j.1751-9004.2009.00170.x

[39] P. Ekman, "Basic emotions," Cognition, vol. 98, no. 1992. pp. 45-60, 1999. https://doi.org/10.1002/0470013494.ch3

[40] A. Dirin, T. H. Laine, and M. Nieminen, "Sustainable Usage through Emotional Engagement: A User Experience Analysis of an Adaptive Driving School Application," Cogn. Technol. Work, p. 25, 2017.

[41] A. Dirin and M. Nieminen, "mLUX :Usability and User experience development framework for m-learning," iJIM, Int. J. Interact. Mob. Technol., 2015.

[42] ISO, "Ergonomics of human-system interaction - Part 210: Human-centred design for interactive systems (ISO 9241-210:2010(E))," ISO. pp. 1-32, 2010.

[43] J. Nielsen, "How many test users in a usability study," Useit. com Jakob Nielsen's Website, pp. 1-5, 2012.

[44] B. Christianson, B. Crispo, J. Malcom, and F. Stajano, Secutiy Protocols XIX: 19 International workshop, Cambridge. Cambridge, UK, 2011. 
[45] D. Hauksdóttir, N. H. Mortensen, and P. E. Nielsen, "Identified adjustability dimensions when generating a product specific requirements specification by requirements reuse," Comput. Ind., vol. 65, no. 6, pp. 952-966, 2014. https://doi.org/10.1016/j.compind. 2014.02.011

[46] A. Lucero, E. Karapanos, J. Arrasvuori, and H. Korhonen, "Playful or Gameful?: creating delightful user experiences," Interactions, pp. 35-39, 2014. https://doi.org/10.1145/ 2590973

[47] K. Kwong Ka Kei, "Effects of Service Delivery on Customer Delight : An Experimental Approach in a Restaurant Chain (Dissertation)," City University of Hong Kong, 2006.

[48] S. S. Liaw, M. Hatala, and H. M. Huang, "Investigating acceptance toward mobile learning to assist individual knowledge management: Based on activity theory approach," Comput. Educ., vol. 54, no. 2, pp. 446-454, 2010. https://doi.org/10.1016/j.comp edu.2009.08.029

[49] G. M. Kim and S. M. Ong, "An exploratory study of factors influencing m-learning success,” J. Comput. Inf. Syst., vol. 46, p. 92-97 ST-An exploratory study of factors influe, 2005.

[50] K. Kusano, M. Nakatani, and T. Ohno, "Scenario-based interactive UI design," Proc. SIGCHI Conf. Hum. Factors Comput. Syst. - CHI '13, p. 391, 2013. https://doi.org/10.1145/2470654.2470710

[51] J. Nielsen, "How to Conduct a Heuristic Evaluation," Useitcom. pp. 1-11, 2002.

[52] D. Gefen, I. Benbasat, and P. Pavlou, "A Research Agenda for Trust in Online Environments,” J. Manag. Inf. Syst., vol. 24, no. 4, pp. 275-286, 2008. https://doi.org/10.2753/ MIS0742-1222240411

[53] D. Harrison McKnight, V. Choudhury, and C. Kacmar, "The impact of initial consumer trust on intentions to transact with a web site: A trust building model," J. Strateg. Inf. Syst., vol. 11, no. 3-4, pp. 297-323, 2002. https://doi.org/10.1016/S0963-8687(02)000203

[54] I. Androulidakis and G. Kandus, "Feeling secure vs. being secure the mobile phone user case," in Lecture Notes of the Institute for Computer Sciences, Social-Informatics and Telecommunications Engineering, 2012, vol. 99 LNICST, pp. 212-219.

\section{Authors}

Amir Dirin has a PhD in usability engineering from Aalto University in Finland. He is a principal lecturer in Business Information Technology Department at the Haaga-Helia University of Applied Sciences. Amir has strong research background in mobile learning application design \& development e.g., AR/VR/XR learning, adaptive learning, usability, and user experience of mobile learning application design and development.

Teemu H. Laine received a $\mathrm{PhD}$ in Computer Science from the University of Eastern Finland in 2012. He worked more than five years as Assistant Professor at the Ajou University in the Republic of Korea before assuming his current position as Associate Professor at the Luleå University of Technology in Sweden. His current research focuses on context-aware games for education and well-being, and his other research interests include augmented and virtual reality, software architectures, and ICT for development.

Ari Alamäki received a $\mathrm{PhD}$ in technology education in 1999, and currently he is a principal lecturer at Haaga-Helia University of Applied Sciences, Finland. His cur- 
rent research focuses on customer behavior in digital channels, digital tourism marketing, and business perspectives on big data analytics. His work has been published in both refereed scientific journals and practically oriented business journals and books. He also has over 12 years of experience in business consulting and software development.

Article submitted 05 November 2017. Resubmitted 05 February 2018. Final acceptance 05 March 2018.Final version published as submitted by the authors. 